\title{
Evaluation of Prevention of Mother to Child Transmission of Human Immunodeficiency Virus Program (Option B+), Kadoma City, Zimbabwe, 2016
}

\author{
Article by Pamela Nyaradzai Magande ${ }^{1,}$ Notion Gombe ${ }^{1,}$ Donewell Bangure ${ }^{1}$, Mungati \\ More $^{1,}$ Tshimanga Mufuta ${ }^{1}$, Daniel Chirundu ${ }^{2}$ \\ ${ }^{1}$ Department of Community Medicine, University of Zimbabwe \\ Email:pmagande@gmail.com \\ gombent@yahoo.com \\ bangured@yahoo.com \\ mungatim@yahoo.com \\ tshimangamufuta@gmail.com \\ ${ }^{2}$ Kadoma City Health Department \\ Email:dchirundu@me.com
}

\begin{abstract}
Background: In 2013, Zimbabwe adopted Option B+, lifelong anti-retroviral therapy (ART) for all pregnant and breastfeeding HIV positive women and Nevirapine prophylaxis for their infants as a PMTCT method. Kadoma city started implementing the same in 2014. An evaluation was done to assess progress and determine reasons for loss of follow-up to advice and improve the program.

Methods: A process-outcome program evaluation using a logical framework was conducted. Pretested interviewer administered questionnaires, checklists and monthly reports were used for data collection. Epi Info 7 was used to calculate means and frequencies. Microsoft-Excel 2013 was used to consolidate monthly reports.

Results: Thirty health workers and 43 Option B+ clients were recruited. Although resources were limited, all the 324 women who tested positive in 2014 and 2015 received ART. CD4+ monitoring increased from 54\% in 2014 to $65 \%$ in 2015. All the 240 exposed infants identified within 72 hours received Nevirapine prophylaxis in 2014 and 2015. HIV positivity at six weeks in infants decreased from $4 \%$ in 2014 to $2 \%$ in 2015. Reasons given by health workers for loss to follow-up were: clients' limited understanding (37\%), poor tracking mechanisms (23\%), mobility of clients (20\%), religious beliefs (17\%) and side effects (3\%). Clients' involvement in community support groups was poor (3\%).

Conclusions: Despite limited resources, there was an improvement in Option B+ services. Reasons for loss to follow-up include poor tracking mechanisms, clients' mobility, religious beliefs and side effects. Clients have been referred to community support groups and retention has improved.
\end{abstract}

Keywords: PMTCT, anti-retroviral therapy, Option B+, Kadoma, Zimbabwe Word count: 244

\section{Introduction}

The World Health Organization estimates 3.2 million children are living with Human Immuno-deficiency Virus (HIV) worldwide [1]. Ninety-one percent of these are in SubSaharan Africa [2]. In Zimbabwe, there are an estimated 144,575 children under the age of 14years living with HIV [3]. Mother to child transmission of HIV accounts for $90 \%$ of the HIV infections among children in Zimbabwe [4]. Therefore the need for effective Prevention of Mother to Child Transmission (PMTCT) of HIV cannot be overemphasized.

Zimbabwe has shown commitment to PMTCT since 1999. The initial pilot project has become a fully-fledged national program [4]. In that pilot, single dose Nevirapine was being used for PMTCT. In 2010, Zimbabwe adopted Option A as the national PMTCT regimen. 
This includes distinct treatment and prophylaxis components for antiretroviral therapy (ART) during pregnancy and breastfeeding [5]. In 2011, Zimbabwe was named one of 22 priority countries in the Global Plan for elimination of mother-to-child transmission of HIV [6]. In 2013, Option B+ (lifelong ART for pregnant and breastfeeding HIV positive women) was adopted [7, 8]. Use of the Option $\mathrm{B}+$ is aimed at reducing mother to child transmission of HIV to less than 5\% [9]. To achieve this, at least $90 \%$ of the mothers should be retained in care.

Kadoma, Zimbabwe started implementing Option B+ in 2014 to reduce the number of new HIV infections among children by $90 \%$ and to reduce the number of AIDS-related maternal deaths by 50\%. Pregnant and breastfeeding women who test HIV positive are initiated on lifelong ART. Their infants receive Nevirapine and Cotrimoxazole prophylaxis. These children are tested for HIV and initiated on ART if they are positive. This is guided by the national guidelines [7]. Since the introduction of Option B+ in 2014, there had not been any evaluation documented or otherwise to assess program performance. At the same time, the target of retaining at least $90 \%$ of the clients had not been met since program inception. We evaluated the program and identified the reasons for loss to follow up to advise and improve program implementation.

\section{Methods}

A program evaluation using the logical framework for process-outcome was conducted in Kadoma City, Zimbabwe. (Table 1). The four health centers under Kadoma City Council that provide PMTCT services were included in the study. All the 30 health workers who provide PMTCT services were interviewed. Using StatCalc and the study by Tenthani et.al. (2014)in which $17 \%$ of the clients appeared lost to follow-up at 6 months, at 95\% confidence level, given that the number of clients registered in care at the time of the study was 189, the calculated sample size for the clients is 42 [10]. Clients were systematically sampled from the appointment registers. Interviewer administered questionnaires derived from the log-frame were used to subjectively assess the inputs and processes being carried out under Option B+. The questionnaires were translated into the local language and pretested at Kadoma General Hospital. Checklists were used to objectively assess the availability of inputs. Data were captured from the questionnaires and analyzed using Epi Info $7^{\mathrm{TM}}$ (CDC, 2012). Before analyzing, frequencies were run for each variable to assess for missing variables. Using the questionnaires, the missing information was added into Epi Info 7. Frequencies and means were calculated using this software. Monthly reports were consolidated and analyzed to assess outputs and outcomes using Microsoft Excel 2013. Written informed consent was obtained from all participants for both participation and publication. Permission and ethical approval was obtained from the Health Studies Office.

\section{Results}

\section{Demographic characteristics}

Thirty health workers were recruited in the study. Of these, 83 were female and $97 \%$ were nurses. The median age was 39.5 years $\left(\mathrm{Q}_{1}=35 ; \mathrm{Q}_{3}=48.5\right)$ and the median time in post was 5years $\left(\mathrm{Q}_{1}=1.5 ; \mathrm{Q}_{3}=13.5\right)$. (Table 2).

\section{Inputs for Option B+ in Kadoma city, 2016}

There were three months stocks of HIV test kits, adult medicines. Each of the four sites had a working cell phone and landline for communication. They also had functional laptops for data capturing. However, there were two months supplies of paediatric ART medicines and Cotrimoxazole was out of stock. Only two of the clinics had CD4+ machines. Twentynine nurses and one primary care counsellor were providing services against a staff establishment of 36 and four respectively. (Table 3) 


\section{Processes and outputs of the PMTCT (Option B+) program in Kadoma city, 2014-2015}

In 2014, all the 2,846 women who presented to the various entry points eligible for HIV testing were offered, counselled and tested. In the antenatal clinics, of the 1,210 tests performed, $78 \%$ were first time tests. Thirteen percent (157) of the clients tested HIV positive in ANC, only 8\% (96) were initiated on ART. In labour and delivery, of the 58 women who were eligible for HIV tests, $10 \%$ (6) were positive and 5\% (3) were initiated on ART. In postnatal clinics, of the 223 women who were tested, $6 \%$ (13) were positive but the number of women initiated on ART is $16 \%$ (36) of those tested.

In 2015, of the 2,179 tests performed under Option B+, 76\% were first time tests. Of these, $6 \%$ (131) tested positive and the same 6\% (131) were initiated on ART. In labour and delivery, of the 96 women who were eligible for HIV tests, $6 \%$ (6) were positive and 6\% (6) were initiated on ART. In post-natal clinics, of the 571 women who were tested, $2 \%$ (11) and the same were initiated on ART. ART was being initiated regardless of the presence or absence of initial CD4+ counts and the levels of the same. (Figure 1).

All the 240 exposed infants who were identified within 72 hour received Nevirapine prophylaxis in 2014 and 2015. Amongst those who were identified after 73 hours, two (7\%) and nine (17\%) did not receive Nevirapine prophylaxis in 2014 and 2015 respectively. (Figure 2)

Of the 152 infants tested in 2014, 96(63\%) received their results. In 2015, 246(72\%) of 338 infants received their results. All the six infants (4\%) who tested DNA PCR positive in 2014 were initiated ART. The same was done for all five infants (2\%) who tested positive in 2015. (Figure 2)

CD4+ count is being used to monitor clients on treatment. This is offered at baseline and every six months. Ninety-five (54\%) of the 176 clients who were eligible for CD4+ testing received the test in 2014. In 2015, of the 263 clients who were eligible for CD4+ testing, $170(65 \%)$ managed to get the test.

\section{Outcomes of the PMTCT (Option B+) program in Kadoma city, 2014-2015}

There were no recorded deaths among women who had been enrolled under the PMTCT (Option $\mathrm{B}+$ ) program. HIV positivity among infants decreased from 4\% in 2014 to $2 \%$ in 2015.

\section{Reasons for loss to follow-up in Kadoma city, 2016}

Limited understanding on the part of clients (37\%), poor tracking mechanisms (23\%), mobility of clients (20\%), religious beliefs (17\%) and side effects (3\%) were given as reasons for loss to follow-up by health workers in Kadoma City. Twelve clients admitted to have faced problems since initiation of treatment. Of these nine cited side effects while three cited marital problems. Only $3 \%$ of the clients were in community support groups.

\section{Discussion}

The reasons for loss to follow-up were clients' limited understanding, religious beliefs and side effects among others. This is consistent with Tweya (2014) who reported similar results in Malawi [11]. In order to retain clients in care, interventions should aim at addressing the problems that the clients raise. One way of doing do is by allowing people who have gone through the same difficulties to advise those who are new to the program. This is where community support groups come in. In this study, only 3\% of the clients were in support groups. Tenthani et.al. (2014) and Kalembo et.al. (2012) concluded that interventions such as community or family-based models of care could improve retention in care and indirectly effectiveness of Option B+ [10,12]. Applying the same in Kadoma could improve retention of clients.

In Kadoma there were fewer health workers, $\mathrm{CD}+$ machines and paediatric medicines than required for the provision of PMTCT services. It could have come about as a result of the 
government directive to freeze all post and not hire new employees. While it is expected given the current economic conditions, it could result in health worker burnt-out compromising the quality of services being provided. It is possible that the stock-out of paediatric Cotrimoxazole could have come about because the 'overworked' health workers may have forgotten to order the medicines.

As a result of the shortage of $\mathrm{CD}+$ machines, not all the clients who needed the service managed to get it. Trying to cater for all the clients can result in frequent breakdowns of the machines and it becomes a vicious cycle. This is consistent with an evaluation by NuwagabaBiribonwoha et.al. (2007) who also reported shortages of staff and supplies in Uganda [13]. According to Gallant et.al (2011) the effectiveness of patient management is affected by clinic staffing levels and available resources [14]. There is therefore need to advocate for more employees to meet staffing requirements and engage all stakeholders to source for more equipment.

Not all the women who needed ART were initiated in 2014. This could be explained by the fact that the program was still starting and therefore the performance not yet optimal. The transition from one set of guidelines to another could have resulted in women being missed with some health workers still using the old system. The health workers were being given onjob training and this process takes time. This is supported by the fact that when we come to 2015, all the women who needed ART were initiated signalling program maturity. While onjob training is effective and cheap there is need to sensitise all health workers on new guidelines so that a new program can easily take off. This can easily be done by conducting meetings to update all the health workers and displaying new guidelines on charts in the clinics.

The pregnant and breastfeeding women were initiated on ART regardless of absence or level of CD4+ counts. This practice is in line with the 2013 Zimbabwean and World Health Organisation treatment guidelines for HIV management [7, 8]. It allows pregnant and breastfeeding women to be expedited into care even in resource limited settings such as ours.

According to the national treatment guidelines all HIV exposed infants should be initiated on Nevirapine prophylaxis [8]. Although a small percentage of infants was missed in Kadoma, program performance was better than in the Oromia region in Ethiopia. Balcha et.al. (2011) reported that in this region, $71 \%$ babies born to HIV-positive mothers did not access prophylactic medicine [15].

It was however difficult to assess HIV positivity beyond six weeks of age since the monthly reports were limited to six weeks after delivery. No further analysis beyond this age was possible for the infants. There is need to expedite the use of data collection tools that track the mother-baby pairs beyond six weeks. Further study to assess HIV positivity in children beyond six weeks would shed more light regarding the success of Option B+.

\section{Conclusion}

In Kadoma, the PMTCT (Option B+) program was being carried out following the national guidelines. The program gradually improved over time and in 2015, there was good program performance in spite of limited resources. The reasons for loss to follow-up include clients' limited understanding, poor tracking mechanisms, and mobility of clients, religious beliefs, side effects and marital problems. Clients were referred to community support groups and retention has improved.

\section{Acknowledgements}

We are grateful to Kadoma City Council for their support during the study. We are also grateful to the health workers in Kadoma for their day to day hard work and their cooperation during the conduct of this study. The authors are also grateful to the Zimbabwe MPH-FETP program and the Centers for Disease Control and Prevention (CDC) Zimbabwe for funding and technical assistance. 


\section{References}

[1]. WHO, HIV and AIDS, Treatment of children living with HIV, http://www.who.int/hiv/topics/paediatric/en/ Accessed 29 September 2015

[2]. Averting HIV and AIDS, Children, HIV and AIDS, http://www.avert.org/children-and-hivaids.htm, Accessed 29 September 2015

[3]. Zimbabwe National Statistics Agency (ZIMSTAT) and ICF International. 2012. Zimbabwe Demographic and Health Survey 2010-11. Calverton, Maryland: ZIMSTAT and ICF International Inc.

[4]. Ministry of Health and Child Care, Report of Mid-Term Review of the National eMTCT Strategic Plan 2011 - 15, National AIDS and Tuberculosis Unit,August - September 2013

[5]. Ministry of Health and Child Care, Zimbabwe. An Operational Plan for the Nationwide Transition to Option B+ in Zimbabwe: September 2013-November 2014. Available at:

http://www.nac.org.zw/sites/default/files/MoHCC_OpPlan_081113.pdf. Accessed 29 September 2015

[6]. Joint United Nations Programme on HIV/AIDS. Global Plan towards the Elimination of New HIV Infections among Children by 2015 and Keeping Their Mothers Alive. Geneva, Switzerland: UNAIDS; 2011.

[7]. World Health Organization. Consolidated Guidelines on the Use of AntiretroviralDrugs for Treating and Preventing HIV Infection: Recommendations for a Public Health Approach. Geneva, Switzerland: WHO Department of HIV/AIDS; 2013.

[8]. Ministry of Health and Child Care, Guidelines for Antiretroviral Therapy for the Prevention and Treatment of HIV in Zimbabwe, 2013,

[9]. Recommendations for use of antiretroviral drugs in pregnant HIV-1 infected women for maternal health and interventions to reduce perinatal HIV-1 transmission in the United States. Washington: US Public Health Service Task Force; 2005.https://aidsinfo.nih.gov/contentfiles/perinatalgl.pdf Accessed 29 September 2015

[10]. Tenthani L, Haas AD, Tweya H, Jahn A, van Oosterhout JJ, Chimbwandira F, et al. Retention in care under universal antiretroviral therapy for HIV-infected pregnant and breastfeeding women ('Option B+') in Malawi, AIDS, 2014 Feb 20;28(4):589-98.

[11]. Tweya H, (2014). Loss to follow-up among women in Option B+ PMTCT programme in Lilongwe, Malawi: Understanding outcomes and reasons, presentation at International AIDS Society.

[12]. Kalembo FW, Zgambo M, Loss to Followup: A Major Challenge to Successful Implementation of Prevention of Mother-to-Child Transmission of HIV-1 Programs in Sub-Saharan Africa, ISRN AIDS, 2012, 589817, 10

[13]. Nuwagaba-Biribonwoha H, Mayon-White RT, Okong P, Carpenter LM, Challenges faced by health workers in implementing the prevention of mother-to-child HIV transmission (PMTCT) programme in Uganda, Journal of Public Health, Vol. 29, No. 3, pp. 269-274

[14]. Gallant J, Adimora A, Carmichael J, Horberg M, Kitahata M, Quinlivan E, et.al.Essential Components of Effective HIV Care: A Policy Paper of the HIV Medicine Association of the Infectious Diseases Society of America and the Ryan White Medical Providers Coalition, 2011,Oxford University Press,

[15]. Balcha TT, Lecerof SS, Jeppsson AR, Strategic Challenges of PMTCT Program Implementation in Ethiopia, J IntAssoc Physicians AIDS Care (Chic), 2011, 10(3):187-92. 
Texila International Journal of Public Health

Volume 4, Issue 3, 2016

\section{Tables}

Table 1. Logical Framework (adapted from WHO HIV Consolidated Strategic Information guide)

\begin{tabular}{|c|c|c|c|c|}
\hline Inputs & Processes & Outputs & Outcomes & Impacts \\
\hline $\begin{array}{l}\text { Human Resources } \\
\text { Medicines } \\
\text { Consumables } \\
\text {-gloves } \\
\text {-delivery packs } \\
\text {-prophylaxis } \\
\text { medication } \\
\text { Communication } \\
\text { Vehicles and } \\
\text { transport } \\
\text { Diagnostic aids-e.g. } \\
\text { test kits } \\
\text { Stationery } \\
\text { Space and } \\
\text { infrastructure }\end{array}$ & $\begin{array}{l}\text { Health workers } \\
\text { training on Option } \\
\mathrm{B}+ \\
\text { Community } \\
\text { mobilisation and } \\
\text { sensitization } \\
\text { Health education to } \\
\text { pregnant women, } \\
\text { new mothers and } \\
\text { their partners } \\
\text { Counselling of } \\
\text { pregnant women, } \\
\text { new mothers and } \\
\text { their partners } \\
\text { Initiating eligible } \\
\text { clients on ART }\end{array}$ & $\begin{array}{l}\text { Number of health } \\
\text { workers trained on } \\
\text { Option B+ } \\
\text { Number of } \\
\text { pregnant women } \\
\text { and their partners } \\
\text { counselled and } \\
\text { tested for HIV } \\
\text { Number of HIV } \\
\text { positive pregnant } \\
\text { women, new } \\
\text { mothers and infants } \\
\text { initiated on ART }\end{array}$ & $\begin{array}{l}\text { \% staff trained in } \\
\text { Option B+ } \\
\% \text { pregnant } \\
\text { women and new } \\
\text { mothers tested } \\
\text { for HIV } \\
\% \text { pregnant HIV } \\
\text { positive women } \\
\text { and new mothers } \\
\text { initiated on ART } \\
\% \text { pregnant HIV } \\
\text { positive women } \\
\text { and new mothers } \\
\text { retained in care } \\
\text { at } 6 \text { months } \\
\% \text { HIV exposed } \\
\text { infants identified } \\
\text { within } 72 \text { hours } \\
\% \text { HIV positive } \\
\text { infants initiated } \\
\text { on ART }\end{array}$ & $\begin{array}{l}\text { Reduction of } \\
\text { HIV } \\
\text { transmission to } \\
\text { children to } 5 \% \\
\text { Reduction of } \\
\text { maternal } \\
\text { mortality by } \\
50 \%\end{array}$ \\
\hline
\end{tabular}

Table 2. Demographic Characteristics of Health Workers in Option B+ in Kadoma, 2016

\begin{tabular}{ll}
\hline Variable & $\mathrm{n}(\%)$ \\
\hline Sex & $25(83)$ \\
Female & $5(17)$ \\
Male & \\
Designation & $14(47)$ \\
Midwife & $12(40)$ \\
Registered General Nurse & $3(10)$ \\
Sister In-Charge & $1(3)$ \\
Primary Care Counsellor & $39.5(35 ; 48.5)$ \\
Median age in years $\left(\mathrm{Q}_{1} ; \mathrm{Q}_{3}\right)$ & $5(1.5 ; 13.5)$ \\
Median years in post $\left(\mathrm{Q}_{1} ; \mathrm{Q}_{3}\right)$ & \\
\hline
\end{tabular}


Table 3. Required Inputs for Option B+ in Kadoma City, 2016

\begin{tabular}{|c|c|c|}
\hline & Available & Target \\
\hline \multicolumn{3}{|l|}{ Human Resources } \\
\hline Nurses & 29 & 36 \\
\hline Primary care counsellor & 1 & 4 \\
\hline \multicolumn{3}{|l|}{ Medicines } \\
\hline Adult & -Three months' supply & -Three months' supply \\
\hline \multirow[t]{2}{*}{ Paediatric } & -Two months' supply- & -Three months' supply- \\
\hline & $\begin{array}{l}\text { Cotrimoxazole out of } \\
\text { stock }\end{array}$ & Three months' supply \\
\hline \multicolumn{3}{|l|}{ Diagnostic aids } \\
\hline Test kits & -Three months' supply & -Three months' supply \\
\hline CD4+ machines & 2 & One at each site(5) \\
\hline Viral load machines & 0 & 1 \\
\hline \multicolumn{3}{|l|}{ Communication } \\
\hline Landline & One at each site & One at each site \\
\hline Cellular phones & One at each site & One at each site \\
\hline Air time & Inadequate & Available on demand \\
\hline Laptop & One at each site & One at each site \\
\hline Internet connectivity & None & Available at all centres \\
\hline
\end{tabular}

\section{Figures}

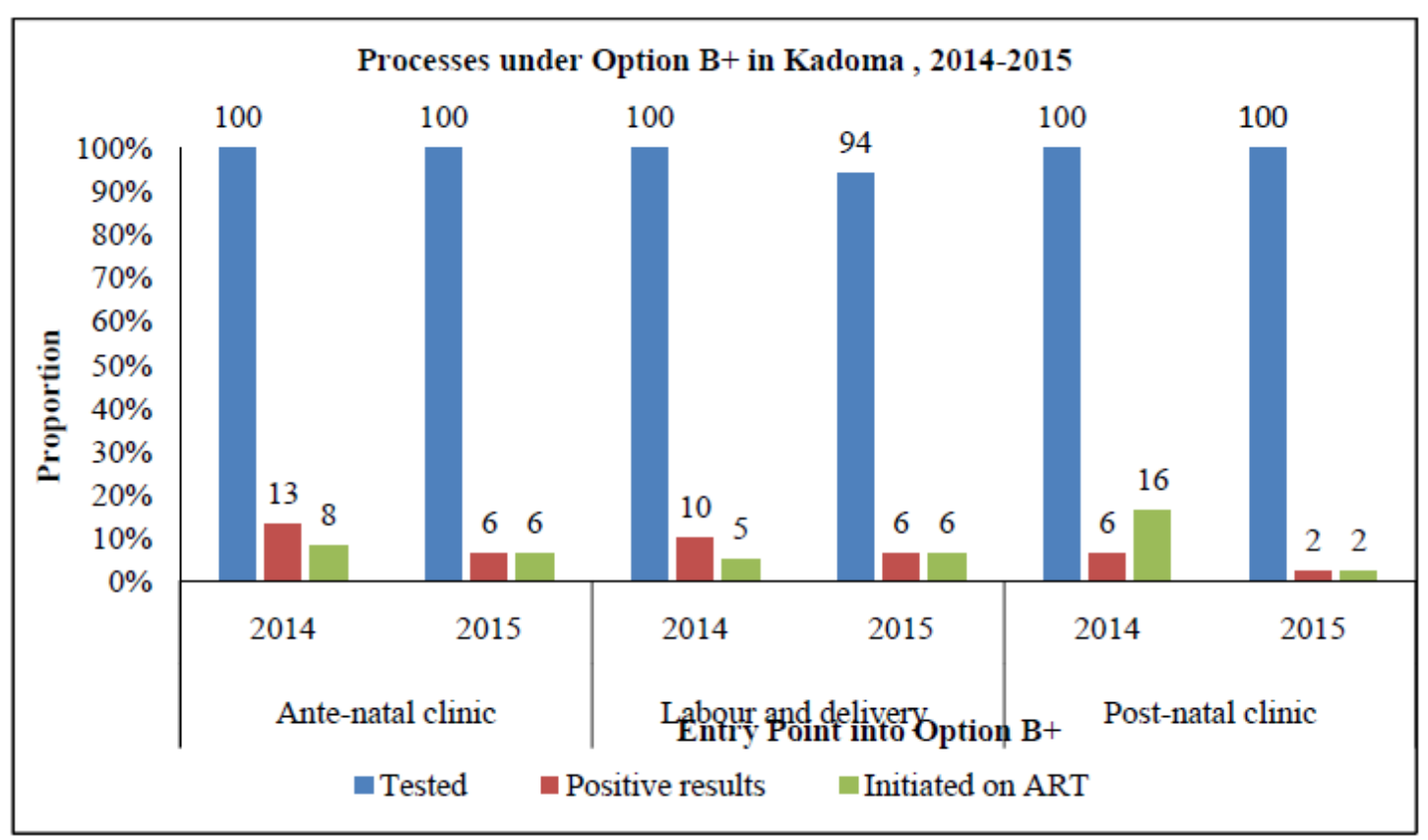

Figure 1. Processes under Option B+ in Kadoma City, 2014-2015 
Texila International Journal of Public Health

Volume 4, Issue 3, 2016

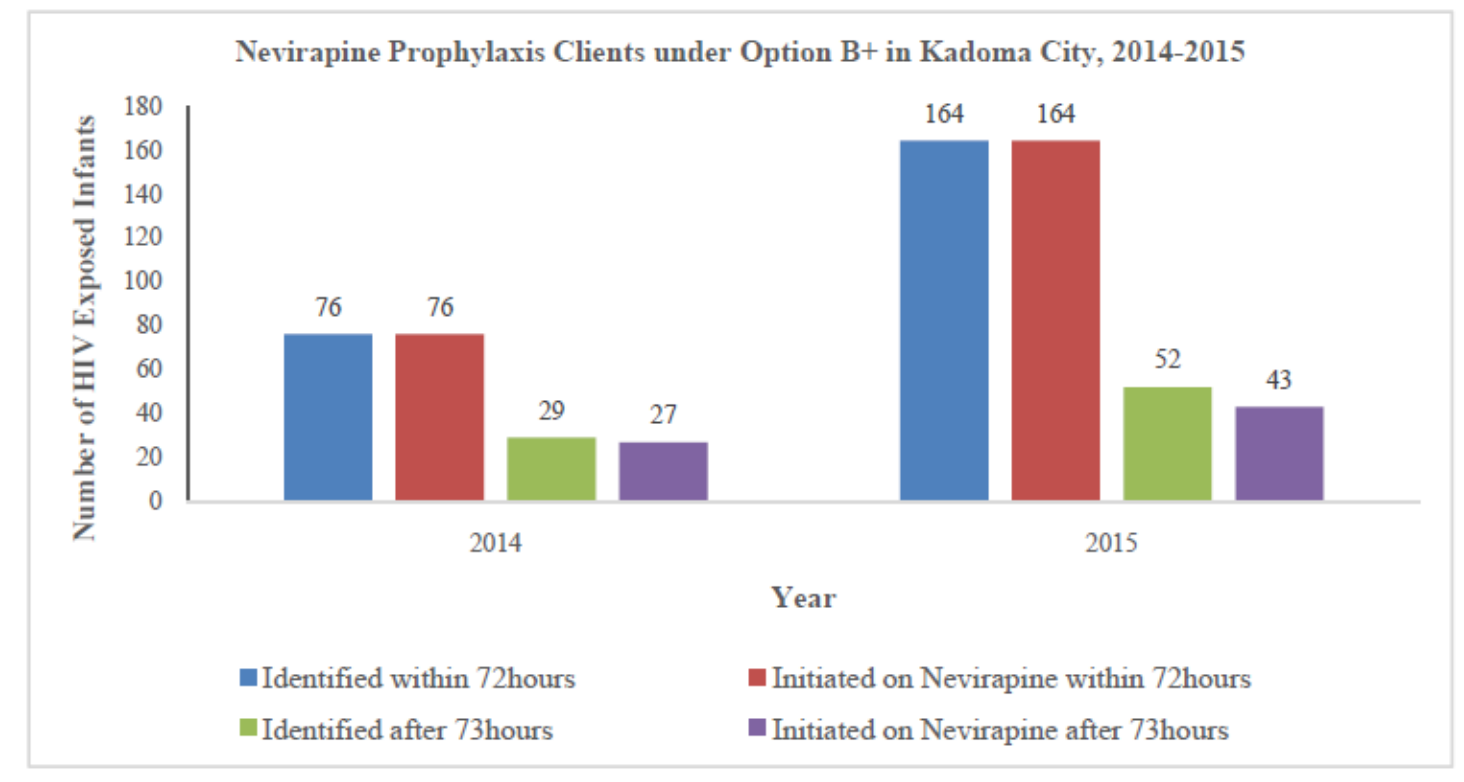

Figure 2: Nevirapine Prophylaxis Clients under Option B+ in Kadoma City, 2014-2015 